\title{
Correlation of the Topographical Arrangement and the Functional Pattern of Tissue-infiltrating Macrophages in Giant Cell Arteritis
}

\author{
Cornelia M. Weyand, ${ }^{\star}$ Annette D. Wagner, ${ }^{\star}$ Johannes Björnsson, ${ }^{\ddagger}$ and Jörg J. Goronzy ${ }^{\star}$ \\ $*$ Department of Medicine, Division of Rheumatology, and the ${ }^{\ddagger}$ Department of Laboratory Medicine and Pathology, Mayo Clinic and \\ Foundation, Rochester, Minnesota 55905
}

\begin{abstract}
End organ ischemia, fragmentation of elastic membranes, and aneurysm formation in patients with giant cell vasculitis results from an inflammation destroying the mural layers of large and medium sized arteries. Although the inflammatory infiltrate extends through all layers of the affected blood vessel, the most pronounced changes involve the intima and the internal elastic lamina. Analysis of the functional profile of tissue infiltrating CD68 + cells demonstrates that different subsets of macrophages can be distinguished. TGF $\beta 1$-expressing CD68 + cells coproduce IL-1 $\beta$ and IL-6, are negative for inducible nitric oxide synthase (iNOS), and exhibit a strong preference for localization in the adventitia. The adventitial homing of TGF $\beta 1+$ CD68 + cells places them in the vicinity of IFN- $\gamma$ secreting CD4 $+\mathrm{T}$ cells which also accumulate in the exterior layer of the artery. Conversely, iNOS expressing CD68 + cells are negative for TGF $\beta$ and are almost exclusively found in the intimal layer of the inflamed artery. The intimal-medial junction is the preferred site for $72-\mathrm{kD}$ collagenase expressing CD68+ cells. Thus, TGF $\beta 1$-producing macrophages colocalize with activated CD4 $+\mathrm{T}$ cells and home to an area of inflammation which is distant from the site of tissue damage but critical in regulating cellular influx, suggesting that TGF $\beta 1$ functions as a proinflammatory mediator in this disease. iNOS- and 72-kD collagenase-producing macrophages accumulate at the center of pathology implying a role of these products in tissue destruction. These data indicate that the microenvironment controls the topographical arrangement as well as the functional commitment of macrophages. (J. Clin. Invest. 1996. 98:1642-1649.) Key words: vasculitis • TGF $\beta 1$ - metalloproteinase $\cdot$ macrophage differentiation
\end{abstract}

\section{Introduction}

An inflammatory infiltrate in the wall of medium-sized and large arteries is characteristic for giant cell arteritis (GCA). ${ }^{1}$

\footnotetext{
Address correspondence to C.M. Weyand, M.D., Mayo Clinic, 401 Guggenheim Building, 200 First Street SW, Rochester, MN 55905. Phone: 507-284-1650; FAX: 507-284-1086; E-mail: weyand.cornelia@mayo.edu

Received for publication 6 May 1996 and accepted in revised form 25 July 1996.
}

1. Abbreviations used in this paper: AEC, 3-amino-9-ethylcarbazole; GCA, giant cell arteritis; IEL, internal elastic lamina; iNOS, inducible nitric oxide synthase; NGS, normal goat serum; PMR, polymyalgia rheumatica.

J. Clin. Invest.

(C) The American Society for Clinical Investigation, Inc.

0021-9738/96/10/1642/08 \$2.00

Volume 98, Number 7, October 1996, 1642-1649
The infiltrate is composed of T lymphocytes, macrophages, and multinucleated giant cells (1). Typically, B cells are absent. Mechanisms leading to the recruitment of mononuclear cells to the blood vessel wall are beginning to be understood. Specifically, tissue infiltrating T cells are nonrandomly distributed. Selected CD4+ T cells undergo clonal expansion in the lesions. Identical CD4+ T cells have been isolated from independent sites of the vasculitis, strongly suggesting that the recognition of a tissue residing antigen regulates $\mathrm{CD} 4+\mathrm{T}$ cell expansion (2).

Much less is known about the role of macrophages participating in the inflammatory reaction. Multinucleated giant cells are believed to derive from macrophages. We have previously shown that GCA patients have high frequencies of constitutively activated monocytes in the peripheral blood (3). About $80 \%$ of circulating monocytes identified by the expression of the CD68 marker secrete IL-1 and IL-6, not only in patients with full-blown arteritis, but also in the patients with polymyalgia rheumatica (PMR), a forme fruste of the vasculitis. Serum IL-6 levels correlate with the constitutional symptoms of patients (4). In the tissue, at least two subsets of CD68+ cells exist (3). One subset produces metalloproteinases but no IL-1 and IL-6, whereas the other subset releases IL-1 and IL- 6 but no 72-kD collagenase. Activated macrophages potentially contribute to tissue damage but very little information is available on the mechanisms of tissue destruction. Clinical presentations are dominated by tissue ischemia and include blindness, central nervous system malperfusion, and aneurysm formation. The histopathological correlates for these clinical symptoms are intimal proliferation and fragmentation of the elastic lamina. How recognition of a disease-relevant antigen can eventually cause a proliferative response in the intimal layer and result in destruction of the elastic arterial tissue needs to be understood.

Medium-sized arteries have a distinct histomorphology. The outermost layer, the adventitia, is believed to supply vasa vasorum to the vessel wall. Circular arrays of smooth muscle cells constitute the media and contribute to the elasticity of the blood vessel wall. A well defined elastic membrane, the internal elastic lamina (IEL), separates the intima from the media. Granulomas formed by inflammatory cells and giant cells tend to focus on the intimal-medial junction. A less distinct external elastic membrane defines the junction between media and adventitia. While it is generally accepted that pathological changes in GCA center around the intima and the internal elastic lamina, recent data indicate that events in the adventitia might be equally important (5). CD $4+$ T cells producing IFN- $\gamma$, expressing IL-2 receptors, and undergoing cell division, are preferentially found in the adventitia and along the external elastic lamina. These data are best compatible with the interpretation that antigen recognition occurs in the adventitia and thus at a site distant from the center of pathology.

The aim of the current study was to examine macrophage function in the infiltrate. Specifically, we were interested in un- 
derstanding the relationship of macrophage function and pathology in the intima and internal media, as well as the consequences of macrophages colocalizing with IFN- $\gamma$-producing CD4+ T cells in the adventitia. Our data show that functional heterogeneity within macrophages correlates with the topography of the infiltrate. Production of inducible nitric oxide synthase (iNOS) and 72-kD collagenase is a feature of macrophages localized in the intima and in the vicinity of the IEL. Conversely, production of TGF $\beta$ and IL- 1 characterizes CD68+ cells residing in the adventitia. We conclude that tissue destructive mechanisms in GCA are related to iNOS and collagenase production. The distinct topography of functional macrophage subsets raises the possibility that components of the microenvironment, such as extracellular matrix, determine functional differentiation, or specific recruitment of macrophages.

\section{Methods}

Patients and tissue specimens. Temporal artery specimens were obtained from 27 patients with GCA. All specimens had typical inflammatory infiltrates and the patients fulfilled the diagnostic criteria for GCA (6).

Antibodies $(A b)$. Monoclonal mouse anti-human TGF $\beta 1 \mathrm{Ab}$ (Antigenix America Inc., Franklin Square, NY), CZD monoclonal mouse anti-human IL-1 $\beta$ Ab (Corning-Hazleton, Vienna, VA), polyclonal rabbit anti-iNOS (Affinity BioReagents, Golden, $\mathrm{CO}$ ), monoclonal mouse anti-human CD68 Ab (PG-M1), monoclonal mouse anti-human $\alpha$-smooth muscle actin, biotinylated rabbit anti-mouse $\operatorname{IgF}\left(\mathrm{ab}^{\prime}\right)_{2}$ fragment (all from Dako Corp., Carpinteria, CA), fluorescein-conjugated goat anti-mouse IgG (Caltag Laboratories, San Francisco, CA), rhodamine-conjugated goat $\mathrm{F}\left(\mathrm{ab}^{\prime}\right)_{2}$ fragment to mouse IgG (Organon-Teknika, Durham, NC), horseradish peroxidase-conjugated streptavidin (Dako Corp.), Vectastain ABC kit-alkaline phosphatase (AP-ABC) (Vector Laboratories, Burlingame, CA), TRITC conjugated donkey anti-mouse IgG (Jackson Immuno Research, West Grove, PA), biotinylated swine anti-rabbit $\operatorname{IgF}\left(\mathrm{ab}^{\prime}\right)_{2}$ (Dako Corp.), polyclonal rabbit anti-72-kD collagenase type IV (provided by Dr. W. G. Steler-Stevenson, National Institutes of Health, Bethesda, MD).

Double immunohistochemistry of paraffin tissue sections. Tissue samples (4- $\mu \mathrm{m}$ serial sections) were deparaffinized and endogenous peroxidase was blocked with methanol/3\% hydrogen peroxide (1:1). Nonspecific binding sites were blocked with $5 \%$ horse serum for $10 \mathrm{~min}$ at room temperature (RT). Sections were incubated with anti-human TGF $\beta 1 \mathrm{Ab}(1: 100)$ for $1 \mathrm{~h}$ at RT and developed by subsequent incubations with biotinylated rabbit anti-mouse $\operatorname{IgF}\left(\mathrm{ab}^{\prime}\right)_{2}$ fragment (1:400), peroxidase-labeled streptavidin (1:500), and 3-amino-9-ethylcarbazole (AEC) substrate solution (Sigma Chemical Co., St. Louis, MO). The specimens were then microwaved in $0.1 \mathrm{mg} / \mathrm{ml}$ Protease XXVII (Sigma Chemical Co.), $0.1 \% \mathrm{CaCl}_{2}$ Tris buffer, $\mathrm{pH} 7.6$, for $48 \mathrm{~s}$ at 700 W. The mouse anti-CD68 mAbs (1:100) were applied and incubated for $30 \mathrm{~min}$ at RT. Slides were developed by subsequent incubations with biotinylated rabbit anti-mouse $\operatorname{IgF}\left(\mathrm{ab}^{\prime}\right)_{2}$ fragment (1:400), Vectastain ABC kit-alkaline phosphatase (AP-ABC) solution (Vector Laboratories) and NBT/X-phosphate buffer (Boehringer Mannheim Biochemicals, Indianapolis, IN). The two adjacent sections were stained with anti-CD68 mAb (1:100) and the anti-smooth muscle actin $\mathrm{Ab}$ (1:50), respectively. Slides were developed by subsequent incubations with biotinylated rabbit anti-mouse $\operatorname{IgF}\left(\mathrm{ab}^{\prime}\right)_{2}$ fragment (1:400), peroxidase labewled streptavidin (1:500), and AEC substrate solution. Sections were then stained with polyclonal rabbit anti-iNOS Ab (1:500) by overnight incubation at $4{ }^{\circ} \mathrm{C}$ and subsequently developed with biotinylated swine anti-rabbit $\mathrm{F}\left(\mathrm{ab}^{\prime}\right)_{2}$ fragment (1:400), $\mathrm{ABC}$ solution, and NBT/X-phosphate buffer.

Adjacent sections were stained with the polyclonal rabbit anti72-kD collagenase type IV Ab (1:50) by overnight incubation at $4^{\circ} \mathrm{C}$ and developed by subsequent incubations with biotinylated swine anti-rabbit $\operatorname{IgF}\left(\mathrm{ab}^{\prime}\right)_{2}$ fragment (1:400), peroxidase labeled streptavidin (1:500), and AEC substrate solution.

Slides stained for TGF $\beta 1$, collagenase type IV, and iNOS, respectively, were scanned by using an IBAS image analysis system to generate composite pictures (Kontron Elektronik, Munich, Germany).

Double immunofluorescence staining. Specimens were deparaffinized. To block remaining nonspecific binding sites, sections were incubated with $5 \%$ normal goat serum (NGS) (Life Technologies, Grand Island, NY) for $2 \mathrm{~h}$ at RT. Anti-human TGFß1 Ab (1:100) was applied and incubated for $1 \mathrm{~h}$ at RT. After washing, slides were incubated with goat anti-mouse IgGFITC-conjugated Ab (1:20) for $30 \mathrm{~min}$ at RT. The specimens were then microwaved in $0.1 \mathrm{mg} / \mathrm{ml}$ Protease XXVII, $0.1 \% \mathrm{CaCl}_{2}$ Tris buffer, $\mathrm{pH} 7.6$, for $48 \mathrm{~s}$ at $700 \mathrm{~W}$. Anti-human IL-1 $\beta$ mAb (1:50) was applied and incubated $1.5 \mathrm{~h}$ at RT in the dark. After washing, the slides were incubated with TRITCconjugated donkey anti-mouse anti-IgG $\mathrm{Ab}$ (1:50) for $45 \mathrm{~min}$ at RT in the dark.

Slides were analyzed using an upright Axiphot fluorescence photomicroscope (Carl Zeiss, Inc., Oberkochen, Germany). The images were captured with an SIT camera (Hamamatsu Phototonics, Hamamatsu City, Japan) and digitized to 256 gray values with an IBAS image analysis system. Data were analyzed for the number of single- and double-positive cells after accounting for background fluorescence and autofluorescence.

In situ hybridization. Cryosections were fixed with $1 \%$ paraformaldehyde in $0.2 \%$ DEPC/PBS (Sigma Chemical Co.) for $5 \mathrm{~min}$ at RT and washed three times. Endogenous peroxidase was blocked for $10 \mathrm{~min}$ at RT with $0.1 \%$ sodium azide/ $3 \%$ hydrogen peroxide buffer. Slides were then incubated with 5\% NGS/DEPC to block nonspecific binding sites. Anti-CD68 (1:100) mAb was applied and specimens were incubated for $30 \mathrm{~min}$ at RT. Slides were developed by subsequent incubations with biotinylated rabbit anti-mouse $\operatorname{IgF}\left(\mathrm{ab}^{\prime}\right)_{2}$ fragment (1:300), peroxidase-labeled streptavidin (1:250), and AEC substrate solution.

Sections were then incubated with $2 \mu \mathrm{g} / \mathrm{ml}$-proteinase K (Boehringer Mannheim Biochemical) for $10 \mathrm{~min}$ at $37^{\circ} \mathrm{C}$, were fixed with cold paraformaldehyde/DEPC/PBS, and incubated for $20 \mathrm{~min}$ at $4^{\circ} \mathrm{C}$. The paraformaldehyde solution was then drained off and specimens were washed three times in $\mathrm{DEPC} / \mathrm{H}_{2} \mathrm{O}$. In situ hybridization with sense and anti-sense probes for TGF $\beta 1$ was performed by using a commercially available kit (R\&D Systems, Inc., Minneapolis, MN). Slides were counterstained with methyl green (Sigma Chemical Co.) and evaluated by determining the percentage of the double-positive cells.

\section{Results}

Functional profile of adventitial CD68+ cells: production of $T G F \beta 1$. GCA is a panarteritis with extension of the infiltrate through all layers of the arterial wall. Although inflammatory cells are also recruited to the adventitia, this region of the artery is not affected by tissue damage. IFN- $\gamma$-producing CD4+ $\mathrm{T}$ cells, however, accumulate in the adventitia indicating a contribution of that anatomical part of the artery to the disease process. To examine the function of macrophages homing to the adventitial layer and localizing in the vicinity of IFN- $\gamma-$ secreting CD4+ T cells, immunohistochemistry with antibodies specific for macrophage-derived proteins was applied. Two-color immunohistochemical stains with anti-CD68 and anti-cytokine antibodies demonstrated that the expression of TGF $\beta 1$ was strongly biased to the adventitia (Fig. 1, $A$ and $B$ ). In tissue sections from 14 patients with a classical histomorphology for GCA, 13 patients had TGFß1+ CD68+ cells in the adventitia and/or in the medial-adventitial junction, and in five patients only were TGF $\beta 1$-staining CD68+ cells encoun- 

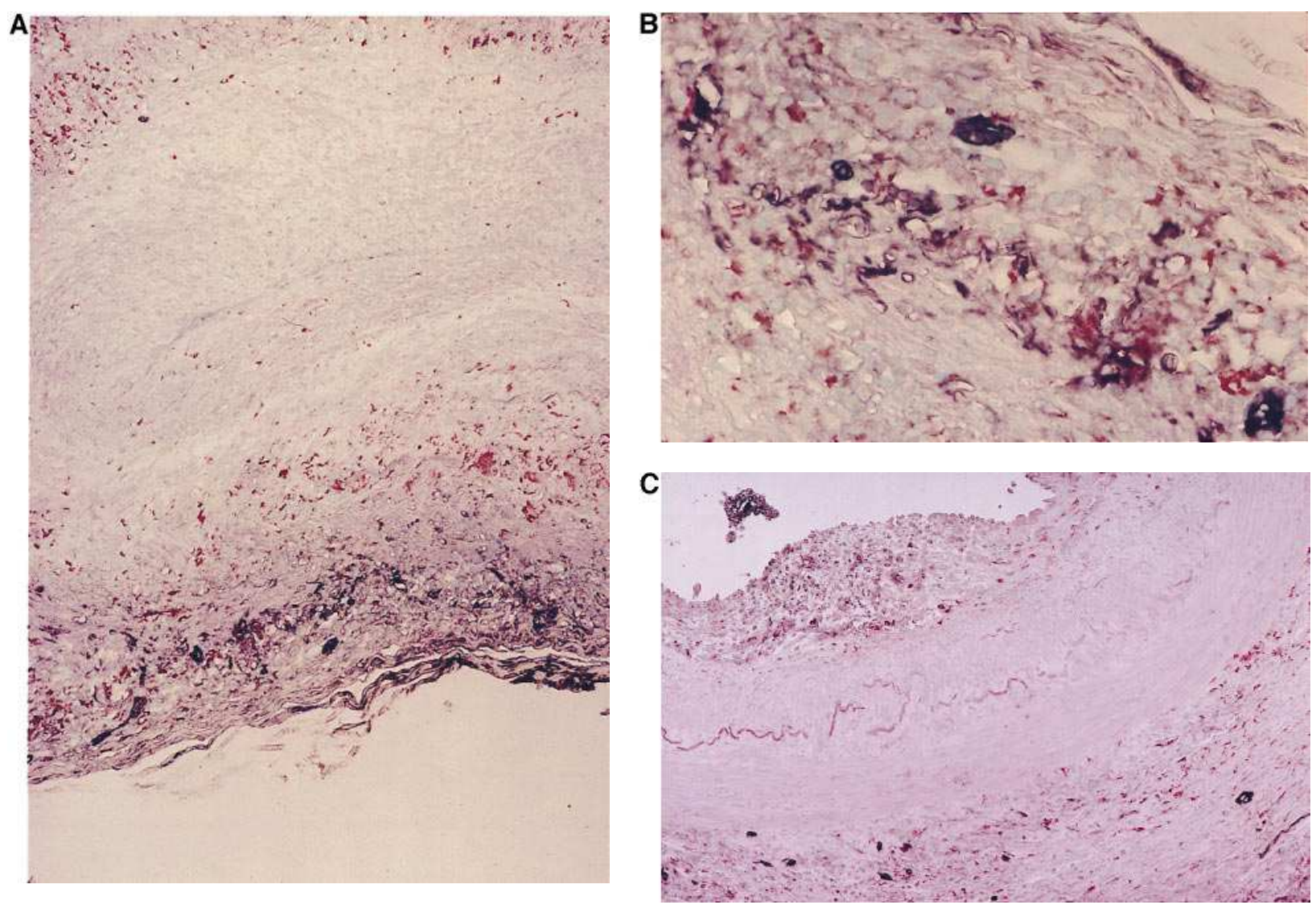

Figure 1. Topography of macrophages expressing TGF $\beta 1$ in GCA. (A) Macrophages (CD68, brown) expressing TGF $\beta 1$ (black) are preferentially located in the adventitial layer of the artery. Oblique slit-like vessel lumen seen at upper center of picture. Anti PG-M1, anti-TGF 31 , at $\times 100$. (B) Coexpression of CD68 (brown) and TGF $\beta 1$ (black) in macrophages in adventitia. Anti-CD68, anti-TGF $\beta 1$, at $\times 400$. (C) A subset of five patients had macrophages expressing TGF $\beta 1$ both in the arterial intima and adventitia. Note fragmented internal elastic lamina and the absence of TGF 31 -expressing cells in the muscular media. Anti-CD68, anti-TGF $\beta 1$, at $\times 100$.

tered in the intima (Fig. $1 C$ ). The localization of TGF 1 -synthesizing CD68+ cells is summarized in Table I. There was a clear preference for this macrophage product to be found in the outer region of the blood vessel. In most cases expression of TGF $\beta 1$ was restricted to areas outside of the external elastic lamina. Occasionally TGF $\beta 1$ stain was seen in CD68+ cells placed around the internal elastic lamina, but such macrophages were infrequent (less than five double-positive cells per high powered field). The media was essentially spared of TGF $\beta 1+$ macrophages. Intimal proliferation was consistently associated with TGF $\beta 1$-producing macrophages mapping to the neointima. Four of five patients with TGF 1 1-producing macrophages localizing to the internal layer of the inflamed artery had intimal proliferation which markedly compromised the lumen and caused almost complete occlusion. The association of intimal proliferation with localized production of TGF $\beta 1$ suggests a role of this growth factor in the proliferative reaction of intimal cell populations.

To determine the frequency of TGF 31 -synthesizing cells in the population of tissue infiltrating macrophages, tissue sections from 10 patients with classical GCA and well maintained arterial morphology were analyzed for the rate of TGFB1 expression in CD68+ cells by two immunohistochemistry. The results of these experiments are given in Fig. $2 A$. The frequency of TGF $\beta 1$ positivity for CD68+ cells was rather uni-
Table I. Localization of TGF 1 -producing CD68+ Cells in the Arterial Wall

Intima IEL* Media EEL $^{\ddagger}$ Adventitia

Without intimal proliferation

Pat. ZE

Pat. LA

Pat. EL

Pat. GR

Pat. LEO

Pat. DR

Pat. TH

Pat. KR

Pat. ST

Pat. WE

With intimal proliferation

Pat. LE

Pat. MO

Pat. CA

Pat. BA

$\begin{array}{lllll}- & - & - & + & - \\ - & - & - & + & + \\ + & - & - & - & + \\ - & - & - & + & + \\ - & + & - & + & + \\ - & - & - & + & + \\ - & - & - & + & + \\ - & - & - & + & + \\ - & + & - & - & - \\ - & - & - & - & + \\ & & & & \\ & & & & - \\ + & + & + & + & + \\ + & + & - & + & + \\ + & - & - & + & + \\ + & + & - & + & +\end{array}$

*Internal elastic lamina, intimal medial junction. *External elastic lamina, medial adventitial junction. 

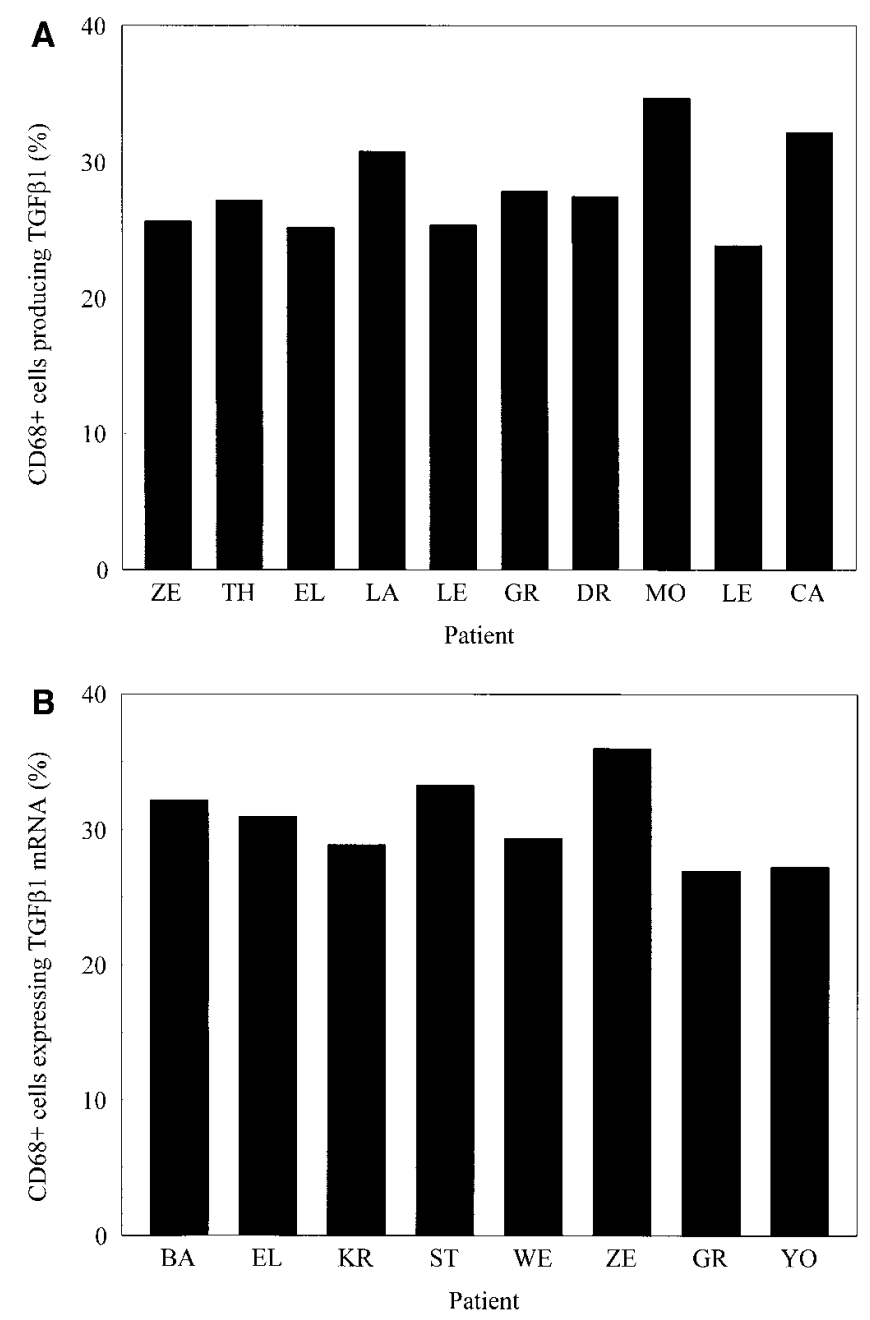

Figure 2. Frequency of TGF $\beta 1$ producing CD68+ cells. Temporal artery specimens were analyzed for TGF $\beta 1$ production by two color immunohistochemistry with anti-CD68 and anti-TGF $\beta 1$ antibodies $(A)$ and by in situ hybridization with TGF $\beta 1$-specific probes and immunohistochemistry with anti-CD68 antibodies $(B)$. A subset of CD68+ cells accounting for approximately $30 \%$ of the total macrophage population produced TGF $\beta 1$. TGF $\beta 1$ production by CD68- cells was not found.

form in the patient cohort and ranged from $24-35 \%$. Thus, about one-third of the macrophages accumulated in the inflamed tissue produced TGF $\beta 1$. The monokines IL-1 $\beta$ or IL-6 were expressed less frequently (data not shown).

In situ hybridization for TGFß1-mRNA was used to confirm that the TGF $\beta 1$ expression was confined to adventitial macrophages. Temporal artery cryosection from eight patients were hybridized with TGF $\beta 1$ mRNA-specific-sense and antisense probes. To identify the producing cell type sections were stained with anti-CD68 specific antibodies. Positive hybridization with the TGF $\beta 1$ probe was limited to cells with the CD68 phenotype. As shown in Fig. 2 B, 25-35\% of CD68+ cells transcribed the TGF $\beta 1$ gene. CD68+ cells expressing TGF 31 mRNA were almost exclusively localized to the adventitia and along the external elastic lamina. Comparison of frequencies of TGF $\beta 1$ protein synthesizing and TGF $\beta 1$ transcribing cells indicated a high concordance of the two techniques. The find-

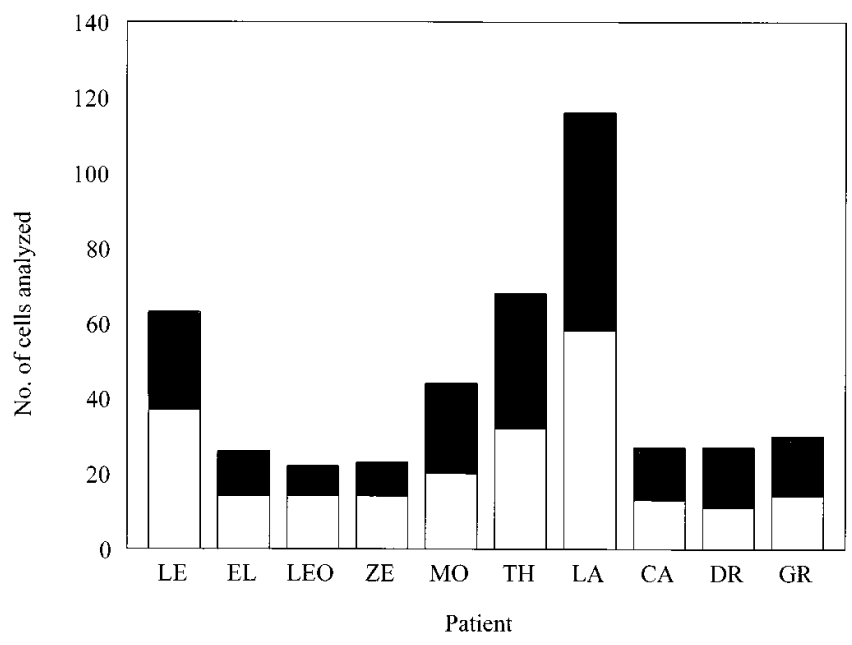

Figure 3. IL-1 $\beta$-producing cells represent a subset of TGF $\beta 1+$ macrophages. Temporal artery specimens of patients with GCA were analyzed for the production of IL- $1 \beta$ and TGF $\beta 1$ by double immunofluorescence. The vast majority of IL-1 $\beta+$ cells coproduced TGF $\beta 1$ (shaded bars), the subset of cells producing only IL-1 $\beta$ (solid bars) was very small. A large subset of macrophages stained positive for TGF $\beta 1$ but negative for IL-1 $\beta$ (open bars).

ing that only one-third of the tissue infiltrating macrophages was specialized to express TGF $\beta 1$ indicated functional heterogeneity of tissue residing macrophages.

Functional profile of adventitial CD68+ cells: production of $I L-1 \beta$. Previous studies have demonstrated that IL- $1 \beta$ and IL- 6 are important mediators in the disease process. IL- $1 \beta$ and IL-6 mRNA can be detected in tissue extracts from patients' temporal artery specimens but not in noninflamed arterial samples (7). IL-6 protein concentrations in the blood of patients with untreated disease are elevated with excellent corre-

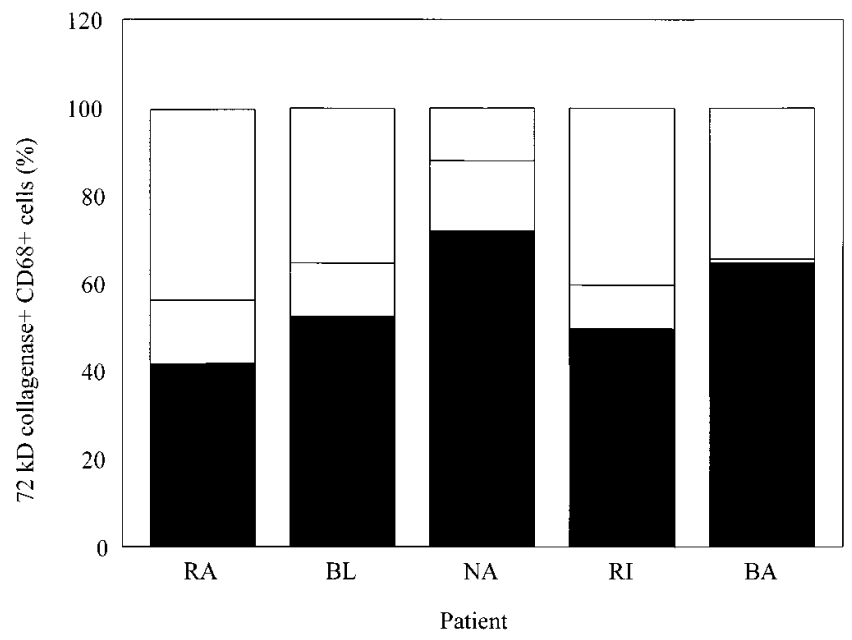

Figure 4. Metalloproteinase producing cells are centered around the internal and external elastic laminas. Tissue sections from temporal arteries were stained with antibodies to CD68 and the 72-kD collagenase. $72-\mathrm{kD}$ collagenase was exclusively produced by a subset of CD68+ macrophages. The majority of collagenase-positive macrophages were found in the intima in the vicinity of the internal elastic lamina (solid bars) and around the external elastic lamina (shaded bars). Few positive cells were found in the media (open bars) and no positive cells were found in the adventitia. 


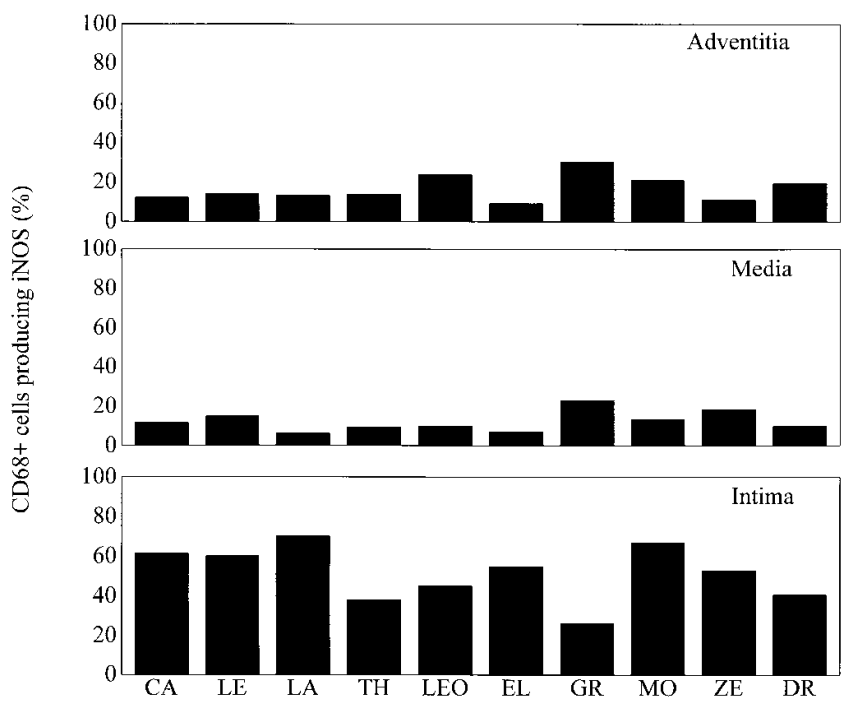

Figure 5. Topographical arrangement of iNOS producing cells. Cells producing iNOS were identified by two color immunohistochemistry with antibodies to iNOS and CD68. A small subset of cells producing iNOS did not express the CD68 marker and could be identified as smooth muscle cells. The majority of iNOS producing macrophages was located in the intima.

lation to disease activity (4). To investigate the relationship of TGF $\beta 1$ and IL-1 $\beta$ production, CD68+ cells were examined for the coproduction of both monokines. Initially we established the cellular source for both products. Immunofluorescence studies with anti-CD68 and anti-monokine antibodies indicated that for both TGF $\beta 1$ and IL-1 $\beta$ CD68+ cells were the exclusive producers in the infiltrate. Neither endothelial cells nor CD68- cells in the inflammatory lesions secreted TGF 31 or IL-1 $\beta$ in amounts which were detectable by antibody staining.

To delineate the relationship between IL-1 $\beta$ and TGF $\beta 1$ producing macrophages, two-color immunofluorescence was applied. Between 30 and $50 \%$ of the TGF $\beta 1+$ cells coproduced IL-1 $\beta$. The fraction of cells synthesizing IL-1 $\beta$ but no TGF $\beta 1$ was negligibly small. Essentially there was a complete overlap in cell populations producing the two products with only a subset of TGF $\beta 1$ producers coproducing IL-1 $\beta$. The results of these studies in 10 patients are shown in Fig. 3. IL-6 production was a feature of CD68+ cells secreting IL-1 $\beta$. The correlation of IL-1 $\beta$ and IL- 6 synthesis was demonstrated by two color immunofluorescence studies using anti-IL-1 $\beta$ and anti-IL-6 reagents (data not shown).

In summary, macrophages localizing to the adventitia and accumulating along the medial-adventitial junction display a defined profile of products including TGF $\beta 1$, IL-1 $\beta$, and IL-6. TGF $\beta 1$ appears to be the dominant cytokine encountered in the largest subset of macrophages always inclusive for the subset of IL-1 $\beta$ producing cells.

Functional profile of intimal and medial macrophages: production of metalloproteinases. The internal layers of the temporal artery are the focus of the disease with intimal proliferation causing vessel occlusion and subsequent ischemia as well as fragmentation of the internal elastic membrane and destruction of the media. The fragmentation of the elastic lamina, a hallmark of the disease, suggests the action of hydrolytic en- zymes. To test the hypothesis that macrophages populating the intima and media are functionally distinct from the adventitial macrophage population, tissue sections from the temporal artery of five patients were stained with antibodies specific for $72-\mathrm{kD}$ collagenase. The antibodies reacted with a subset of CD68+ cells. As shown in Fig. 4, collagenase-releasing CD68+ cells exhibited a preference for the intimal layer. Particularly, collagenase-positive macrophages were identified directly along the IEL. A fraction of CD68+ cells localized in the media expressed the enzyme. Most patients had a small but distinct population of metalloproteinase positive CD68+ cells which were arranged along the external elastic lamina. Adventitial macrophages were essentially negative when stained with the anti-collagenase reagent. The presence of intimal proliferation did not correlate with the localization nor the frequency of collagenase positive CD68+ cells.

Functional profile of intimal macrophages: production of $i N O S$. Nitric oxide plays an important role in the regulation of blood vessel function. Its contribution to inflammation is less well understood but it has been proposed that nitric oxide is involved in tissue destructive events due to its action as a radical gas. To identify cellular components in the inflamed artery with the potential to produce nitric oxide, the expression of iNOS was examined. iNOS production was a feature of tissue infiltrating cells in all 10 biopsy samples analyzed. As shown in Fig. 5, iNOS expression by macrophages was nonrandomly distributed. Only a very small fraction of adventitial macrophages was capable of synthesizing iNOS, whereas the majority of intimal macrophages was stained by the anti-iNOS antibodies. Preference of iNOS expressing CD68+ cells for the interior region of the blood vessel was independent of whether the patient had developed intimal proliferation or not. The external intima and the area surrounding the internal elastic lamina were densely populated by iNOS+ CD68+ cells. CD68+ cells synthesizing iNOS were rarely encountered at the external elastic lamina, suggesting that there is no direct relationship between elastic fibers and iNOS expression.

In contrast to other products analyzed in this study synthesis of iNOS was not exclusive for CD68+ cells. The vast majority of cells reacting with anti-iNOS antibodies had the CD68 phenotype. A small percentage of iNOS+ cells lacked CD68 coexpression. The cell shape and localization suggested the possibility that these cells were smooth muscle cells. This hypothesis was confirmed by applying anti-smooth muscle cell

Table II. Expression of iNOS by Smooth Muscle Cells

\begin{tabular}{lccc}
\hline & Intima & Media & Adventitia \\
\hline & $\%$ & $\%$ & $\%$ \\
Pat. CA & 5.0 & 0.2 & 0 \\
Pat. LE & 7.5 & 1.3 & 0 \\
Pat. TH & 6.3 & 4.0 & 0 \\
Pat. LA & 6.5 & 0.9 & 0 \\
Pat. LEO & 5.6 & 1.3 & 0 \\
Pat. EL & 7.2 & 4.5 & 0 \\
Pat. GR & 6.7 & 1.3 & 0 \\
Pat. MO & 5.8 & 8.4 & 0 \\
Pat. ZE & 4.4 & 0.9 & 0 \\
Pat. DR & 4.8 & 0.6 & 0 \\
& & & \\
\hline
\end{tabular}



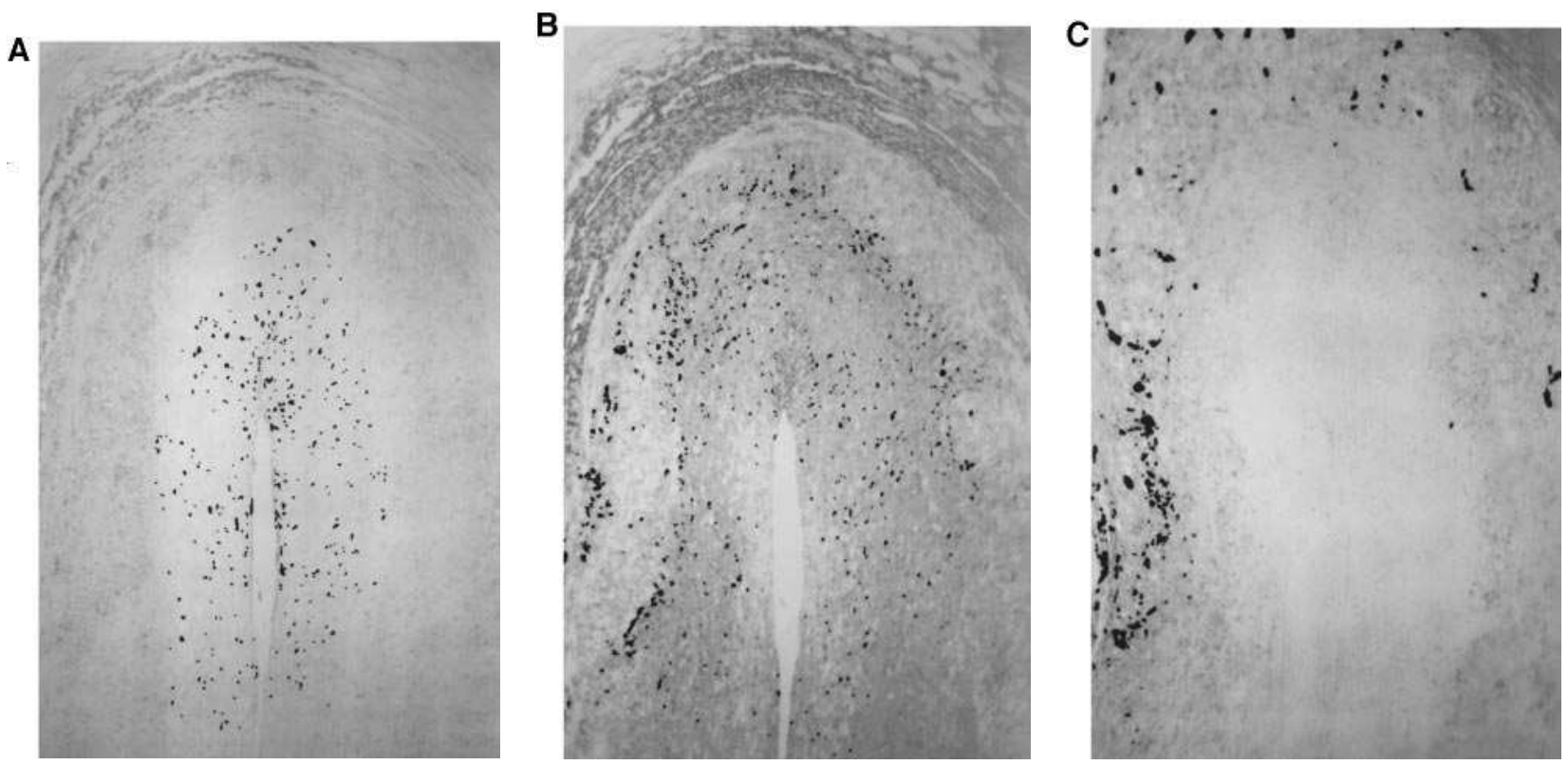

Figure 6. Spatial arrangement of TGF $\beta 1$, metalloproteinase, and iNOS producing macrophages. Consecutive sections of a temporal artery specimen were stained with antibodies for TGFß1 (right), $72-\mathrm{kD}$ metalloproteinase (middle), and iNOS (left). Slides were scanned with an IBAS image analysis system to identify positive cells. At $\times 100$.

actin and anti-iNOS antibodies. Table II summarizes the results of these experiments. A small percentage of smooth muscle cells had intracellular product reactive with iNOS specific antibodies. Interestingly, iNOS + smooth muscle cells again exhibited preference for the intima. While the vast majority of smooth muscle cells are found in the medial layer of the artery, iNOS production was associated with intimal localization of the cells. No smooth muscle cells were encountered in the adventitia. Parallel experiments with tissue sections from noninflamed temporal arteries did not demonstrate iNOS+ smooth muscle cells (data not shown). Thus, induction of iNOS in temporal artery tissue appears to be a consequence of the vasculitic process. The preference of CD68+ and smooth muscle cells synthesizing iNOS to localize to the intima was suggestive of a shared mechanism inducing this enzyme in both cell types.

In summary, studies on the functional profile of tissue infiltrating macrophages revealed that several functional subsets exist. The coproduction of TGF $\beta 1$, IL-1 $\beta$, and IL-6 identified a macrophage subpopulation preferentially residing in the adventitia. Conversely, iNOS producing macrophages located to the intima of the artery. To demonstrate the strict correlation of a functional profile with the anatomical localization distribution patterns of TGF $\beta 1+$, metalloproteinase + , and iNOS + $\mathrm{CD} 68+$ cells were compared by computer-assisted analysis on adjacent sections from the same patient (Fig. 6). This analysis underscored that the functional patterns of the distinct CD68+ populations were mutually exclusive. TGFß1 expression was almost exclusively limited to the adventitial layer. These macrophages stayed external to the external elastic lamina. In contrast, iNOS+ CD68 were almost all inside the internal elastic lamina with clustering in the region bordering the elastic tissue layer. The media appeared to create a functional barrier between the two macrophage subsets, but contained collagenaseproducing macrophages.

\section{Discussion}

GCA is a disease caused by an inflammatory infiltrate composed of T lymphocytes and macrophages. Pathology is induced by destruction of the affected blood vessel wall and by vessel occlusion. The tissue damage is not a diffuse process but rather targeted at defined anatomic structures and is most apparent as generating a lumen compromising neointima, fragmentation of elastic laminas, and scarring in the smooth muscle containing medial layer. Accumulating data indicate that $\mathrm{T}$ cells are recruited to the blood vessel wall where a small population of them acquires the phenotype of an activated $\mathrm{T}$ cell blast and undergoes clonal proliferation (2). All experimental data are indicative of a locally residing antigen inducing the formation of the inflammatory lesions (8). Why the infiltrate has a distinct cellular composition and how tissue destruction occurs, specifically in such a targeted manner, is not understood.

Data presented here demonstrate that several distinct subpopulations contribute to the macrophage infiltrate. At the center of pathology, in the intimal and interior medial layer, macrophages accumulate which are capable of secreting collagenase or express iNOS. We are therefore proposing that the pathological changes typical for GCA are related to the action of hydrolytic enzymes and nitric oxide. Equally important appears to be a macrophage subset accumulating distant from the focus of tissue damage in the adventitial layer of the inflamed artery. These macrophages are characterized by their production of TGF $\beta 1$, IL-1 $\beta$, and IL-6. They probably supply the pro-inflammatory mediators necessary to maintain the inflammatory reaction.

Besides the information on functionally distinct macrophage populations contributing to the vasculitic reaction, the present study provided evidence that inflammatory infiltrates display a distinct topography which appears to be imposed by the 
anatomy of the local environment. The finding that the best predictor for the functional profile of the tissue-infiltrating macrophages is the topographical arrangement within the arterial structure suggests that the microenvironment determines the functional profile of tissue infiltrating cells (9) or regulates the homing of functionally committed cells. Signals must be given to cells migrating through the blood vessel wall-signals which provide the cells information about their localization. Understanding these signals might allow us to disrupt the assembly of inflammatory lesions leading to tissue pathology.

The observation that the adventitia harbors a functionally specialized macrophage subset was unexpected. GCA has been considered a disease of the internal layers of the blood vessel. While we know that the infiltrate spreads through all layers of the arterial wall the adventitia has not been regarded as a disease-relevant region. Thus, the question arises how cells settling in the adventitia could be involved in the vasculitis. We have previously described that the adventitia is the site of preference for a specialized subset of CD4+ T cells, the IFN- $\gamma$-producing CD4 $+\mathrm{T}$ cells (5). IFN- $\gamma+\mathrm{CD} 4+\mathrm{T}$ cells constitute a small subset of the $\mathrm{T}$ cell infiltrate and are almost exclusively found externally of the external elastic lamina. IFN- $\gamma$ represents a key cytokine in the disease process as documented by the finding that temporal artery specimens lacking tissue IFN- $\gamma$ expression also lack a histologically detectable infiltrate. Specifically in patients with PMR, IL-2, but not IFN- $\gamma$, is transcribed in the tissue (7). PMR is a forme fruste of GCA in that it affects the same patient population, causes an identical set of constitutional symptoms, responds to the same therapy, but temporal artery biopsies are free of inflammation by histomorphology (10). We also have demonstrated that giant cell formation is tightly linked with the amount of in situ produced IFN- $\gamma$ (11). IFN- $\gamma$-producing CD4+ T cells frequently express IL-2 receptors, have rearranged the cytoskeletal protein talin and are in the cell cycle. All these features identify them as T cells which have recently contacted antigen $(12,13)$. One conclusion from these data is that a small proportion of $\mathrm{T}$ cells in the infiltrate is antigen activated and that the antigen resides in the adventitial layer.

The adventitia is the port of entry for vasa vasorum. We have therefore suggested that the adventitia is the site of cell entry and that cells migrate into the blood vessel wall through the small capillaries rather than the macroendothelium surrounding the main lumen of the artery (5). Here we describe that TGF $\beta 1 /$ IL-1 $\beta /$ IL-6-secreting macrophages are almost exclusively found in the adventitia and co-localize with IFN- $\gamma$-producing T cells. Although the co-localization does not allow us to conclude a causal relationship between monokine and IFN- $\gamma$ secretion, it is intriguing to suggest that both findings are the consequence of an antigen-recognition event. TGF $\beta 1$ is a growth and differentiation factor which exhibits pro- and antiinflammatory effects. TGF $\beta 1$ used to be considered an antiinflammatory mediator, but recent observations have indicated that the outcome of TGF $\beta 1$ action may be different whether it functions systemically or in the localized environment (14). Systemic TGF $\beta$ appears to be mainly immunosuppressive (15, 16). Within a microenvironment, the proinflammatory effector function of TGF $\beta 1$ and its ability to promote resolution of an inflammatory response and tissue repair are delicately balanced. Local TGF $\beta 1$ production has been shown to be important in chronic inflammation documenting its proinflammatory activities $(17,18)$.
The activity of TGF $\beta$ is not regulated at the transcriptional/ translational level only. TGF $\beta$ is secreted in an inactive form complexed with the latency-associated peptide (19). The in vivo mechanism leading to dissociation and activation are unknown, however, this step appears to be critical in controlling the biological activity. TGF $\beta$-specific antibodies do not distinguish the active and latent form and immunohistological studies have therefore to be interpreted within this limitation.

The most important effect of TGF $\beta 1$ in GCA may relate to its ability to induce increased expression of adhesion molecules as well as to promote chemotaxis for monocytes (20). TGF $\beta 1$ is the strongest known chemotactic agent for monocytes and could thus regulate monocyte influx into the affected blood vessels. Because CD68+ cells are the producer of TGF $\beta$ this would truly represent an autocrine mechanism amplifying inflammation. Induction of adhesion molecules has recently been reported as an TGF $\beta$-mediated function (21). Adventitial localization of TGF $\beta$ synthesis could thus regulate and enhance the recruitment of macrophages. TGF $\beta 1$ induces collagen and fibronectin production, a biological function which has attracted attention in fibrotic diseases (22). Fibrosis is not a feature of the affected blood vessels in GCA indicating that other functional properties of TGF $\beta 1$ are more important in this setting. Also, TGF $\beta 1$-mediated collagen induction in fibroblasts could be counteracted by IFN- $\gamma$ which could be supplied by CD4+ T cells. In summary, based upon their functional profile, adventitial macrophages would be predicted to have a regulatory role in the vasculitis.

Evidence for a growth promoting function of TGFB1 came from the observation that TGF $\beta 1+$ CD68 + cells accumulated at the base of the neointima. In that localization, TGF $\beta 1$ release may contribute to the formation of new tissue. TGF $\beta 1$ was the only cytokine which could be correlated with the presence of intimal proliferation. Neointimal tissue did not contain a higher frequency of iNOS + CD68+ cells.

The colocalization of tissue pathology and iNOS-expressing macrophages is strongly suggestive for a contribution of nitric oxide to tissue destruction. Nitric oxide is a short-lived mediator which functions as a toxic radical gas. A spectrum of biological functions have been associated with nitric oxide which is generated from L-arginine through nitric oxide synthases. Nitric oxide is constitutively produced by endothelial cells and is considered a physiological regulator of blood flow by inducing vasodilatation (23). More recently, interest has focused on its role as a proinflammatory and tissue destructive mediator $(24,25)$. Increased nitric oxide production in inflammatory diseases is mainly mediated by an inducible synthase, iNOS. iNOS production was almost exclusively found in the intima of GCA temporal artery specimens. We were able to identify two cellular sources of iNOS: CD68+ cells and smooth muscle cells. The preference for intimal localization for both cell types suggested as one possibility that iNOS is induced by a common mechanism in the interior part of the vessel wall. Alterations of intima and IEL function are tightly related to the ischemic consequences of GCA and the development of aneurysms. Tissue destructive events in this region of the artery are an important effector mechanism. Suppression of iNOS expression could thus be defined as a therapeutic goal in treating this disease.

Besides the expression of iNOS we were able to map the secretion of metalloproteinases to the internal and medial areas of the temporal artery. $72-\mathrm{kD}$ collagenase could certainly 
have a role in the fragmentation of the elastic tissue and could thus compromise the function of the media and the IEL. Affinity of collagenase-producing macrophages for elastic tissue was suggested by the finding that $72-\mathrm{kD}$ collagenase positive cells also accumulated around the external elastic lamina.

Two crucial questions are how the distinct macrophage populations acquire the functional differentiation, and, which signals guide them to the different anatomical regions of the artery? TGF31/IL-1/IL-6-producing, metalloproteinase and iNOS-expressing CD68+ cells may derive from distinct monocyte/macrophage lineages; alternatively they could represent different stages of differentiation and originate from the same cell. In both scenarios they must receive signals which regulate their homing in the inflammatory infiltrate.

Intima, media, and adventitia do not only differ in the cell types residing or homing to these parts of the vessel wall. Extracellular matrix is a relevant component of defining these anatomical structures. Interaction of tissue infiltrating cells with particular extracellular matrix molecules could be a mechanism interfering with the differentiation of invading cell populations. Alternatively, the correlation of spatial arrangement and function could result from cross-regulation introduced by other cells residing either in the adventitia or in the intima. TGF $\beta 1$ has been reported to inhibit the generation of nitrogen intermediates and to suppress the action of iNOS+ macrophages (26). Dominance of TGF $\beta$ synthesis in the adventitia could thus prevent iNOS expression in that region of the artery. Vice versa, nitric oxide has been shown to inhibit the function of T cells which could explain the preference of IFN$\gamma$-producing $\mathrm{T}$ cells for the adventitia and their sparing of the internal parts of the blood vessel (27). Thus the functional composition of the cellular infiltrate in a defined anatomical area may not be the result of selective cell recruitment but may reflect the consequences of cell-cell interaction (9). Data presented here may provide the basis for alternative therapeutic concepts in GCA. Currently, GCA patients are managed with high doses of steroids given over prolonged periods of time. Regulating the production of TGFß1 may be a desirable goal. TGF $\beta 1$ not only serves as an amplificator of inflammation, but is best known for its anti-inflammatory functions. Fine tuning the production of TGF $\beta 1$ may be one approach of altering the inflammatory process in the artery. Similarly, iNOS could be defined as a potential therapeutic aim. Targeted disruption of macrophage function could lead to improved treatment strategies in GCA.

\section{Acknowledgments}

The authors thank Toni L. Higgins for superb secretarial assistance.

Supported in part by grants from the National Institutes of Health (RO1-AR-42527 and RO1-AR-41974), a clinical science grant (AF 14) and a biomedical science grant (AF 16) from the National Arthritis Foundation, and from the Mayo Foundation both from National Arithritis Found.

\section{References}

1. Cid, M.C., E. Campo, G. Ercilla, A. Palacin, J. Vilaseca, J. Villalta, and M. Ingelmo. 1989. Immunohistochemical analysis of lymphoid and macrophage cell subsets and their immunologic activation markers in temporal arteritis. Influence of corticosteroid treatment. Arthritis Rheum. 32:884-893.
2. Weyand, C.M., J. Schönberger, U. Oppitz, N.N.H. Hunder, K.C. Hicok, and J.J. Goronzy. 1994. Distinct vascular lesions in giant cell arteritis share identical T cell clonotypes. J. Exp. Med. 179:951-960.

3. Wagner, A.D., J.J. Goronzy, and C.M. Weyand. 1994. Functional profile of tissue infiltrating and circulating $\mathrm{CD}^{+} 8^{+}$cells in giant cell arteritis. Evidence for two components of the disease. J. Clin. Invest. 94:1134-1140.

4. Roche, N.E., J.W. Fulbright, A.D. Wagner, G.G. Hunder, J.J. Goronzy, and C.M. Weyand. 1993. Correlation of interleukin 6 production and disease activity in polymyalgia rheumatica and giant cell arteritis. Arthritis Rheum. 36: 1286-1294.

5. Wagner, A.D., J. Björnsson, G.B. Bartley, J.J. Goronzy, and C.M. Weyand. 1996. Interferon gamma producing T cells in giant cell vasculitis represent a minority of tissue infiltrating cells and are located distant from the site of pathology. Am. J. Pathol. 148:1925-1933.

6. Hunder, G.G., D. A. Bloch, B.A. Michel, M.B. Stevens, W.P. Arend, L.H. Calabrese, S.M. Edworthy, A.S. Fauci, R.Y. Leavitt, J.T. Lie, R.W. Lightfoot, Jr., A.T. Masi, D.J. McShane, J.A. Mills, S.L. Wallace, and N.J. Zvaifler. 1990. The American College of Rheumatology 1990 criteria for the classification of giant cell arteritis. Arthritis Rheum. 33:1122-1128.

7. Weyand, C.M., K.C. Hicok, G.G. Hunder, and J.J. Goronzy. 1994. Tissue cytokine patterns in polymyalgia rheumatica and giant cell arteritis. Ann. Intern. Med. 121:484-491.

8. Weyand, C.M., and J.J. Goronzy. 1995. Giant cell arteritis as an antigen driven disease. Rheum. Dis. Clin. N. Am. 21:1027-1039.

9. Doherty, T.M. 1995. T-cell regulation of macrophage function. Curr. Opin. Immunol. 7:400-404.

10. Chuang, T.Y., G.G. Hunder, D.M. Ilstrup, and L.T. Kurland. 1982. Polymyalgia rheumatica: a 10-year epidemiologic and clinical study. Ann. Intern. Med. 97:672-680.

11. Weyand, C.M., N. Tetzlaff, J. Björnsson, and J.J. Goronzy. Disease patterns and tissue cytokine profiles in giant cell arteritis. Arthritis Rheum. In press.

12. Minami, Y., T. Kono, T. Miyazaki, and T. Taniguchi. 1993. The IL-2 receptor complex: its structure, function, and target genes. Annu. Rev. Immunol. 11:245-268.

13. Kupfer, A., S.L. Swain, and S.J. Singer. 1987. The specific direct interaction of helper T cells and antigen presenting B cells. II. Reorientation of the microtubule organizing center and reorganization of the membrane-associated cytoskeleton inside the bound helper T cells. J. Exp. Med. 165:1565-1580.

14. Wahl, S.M. 1994. Transforming growth factor beta: the good, the bad, and the ugly. J. Exp. Med. 180:1587-1590.

15. Lowrance, J.H., F.X. O'Sullivan, T.E. Caver, W. Waegell, and H.D Gresham. 1994. Spontaneous elaboration of transforming growth factor $\beta$ suppresses host defense against bacterial infection in autoimmune MRL/lpr mice. J. Exp. Med. 180:1693-1703.

16. Barral-Netto, M., A. Barral, C.E. Brownell, Y.A. Skeiky, L.R. Ellingsworth, D.R. Twardzik, and S.G. Reed. 1992. Transforming growth factor- $\beta$ in leishmanial infection: a parasite escape mechanism. Science (Wash. DC). 257: $545-548$.

17. Allen, J.B., C.L. Manthey, A.R. Hand, K. Ohura, L. Ellingsworth, and S.M. Wahl. 1990. Rapid onset synovial inflammation and hyperplasia induced by transforming growth factor $\beta . J$. Exp. Med. 171:231-247.

18. Wahl, S.M., J.B. Allen, G.L. Costa, H.L. Wong, and J.R.Dasch. 1993. Reversal of acute and chronic synovial inflammation by anti-transforming growth factor $\beta$. J. Exp. Med. 177:225-230.

19. Sporn, M.B., and A.B. Roberts. 1990. The transforming growth factorßs. In Peptide Growth Factors and Their Receptors. I. M.B. Sporn, and A.B. Roberts, editors. Springer-Verlag, New York. 419 pp.

20. Wahl, S.M., D.A. Hunt, L.M. Wakefield, N. McCartney-Francis, L.M. Wahl, A.B. Roberts, and M.B. Sporn. 1987. Transforming growth factor beta (TGF- $\beta$ ) induces monocyte chemotaxis and growth factor production. Proc. Natl. Acad. Sci. USA. 84:5788-5792.

21. Wahl, S.M., J.B. Allen, B.S. Weeks, H.L. Wong, and P.E. Klotman. 1993. TGF- $\beta$ enhances integrin expression and type IV collagenase secretion in human monocytes. Proc. Natl. Acad. Sci. USA. 90:4577-4581.

22. Roberts, A.B., B.K. McCune, and M.B. Sporn. 1992. TGF-beta: regulation of extracellular matrix. Kidney Int. 41:557-559.

23. Dusting, G.J. 1995. Nitric oxide in cardiovascular disorders. J. Vasc. Res. 32:143-161.

24. Nathan, C. 1992. Nitric oxide as a secretory product of mammalian cells FASEB J. 6:3051-3064.

25. Clancy, R.M., and S.B. Abramson. 1995. Nitric oxide: a novel mediator of inflammation. Proc. Soc. Exp. Biol. Med. 210:93-101.

26. Vodovotz, Y., C. Bogdan, J. Paik, Q.-W. Xie, and C. Nathan. 1993. Mechanisms of suppression of macrophage nitric oxide release by transforming growth factor $\beta$. J. Exp. Med. 178:605-613.

27. Merryman, P.F., R.M. Clancy, X.Y. He, and S.B. Abramson. 1993. Modulation of human $\mathrm{T}$ cell responses by nitric oxide and its derivative, S-nitrosoglutathione. Arthritis Rheum. 36:1414-1422. 